\title{
NUMERICAL SIMULATION OF A SUPERSONIC FREE-MOLECULAR PLASMA FLOW AROUND A CHARGED CONDUCTING CYLINDER NEAR A CONDUCTING SURFACE
}

\author{
Institute of Technical Mechanics \\ of the National Academy of Sciences of Ukraine and the State Space Agency of Ukraine \\ 15 Leshko-Popel St., 49005,Dnipro, Ukraine; e-mail: lazuch.dn@gmail.com
}

By the example of a model problem, this paper considers the effect of neighboring conducting bodies on the collection of charged plasma particles by a conducting cylinder. The aim of the paper is to study the effect of a nearby conducting body on the collection of the ion current by a charged cylinder in a supersonic cross flow of a collisionless nonisothermal plasma. Based on the two-dimensional Vlasov-Poisson system, a supersonic free molecular plasma cross flow past an infinitely long cylinder-strip system was simulated. The problem was solved numerically by a finite-difference relaxation method with splitting by physical processes on nested grids. When calculating the electronrepulsing locally equilibrium self-consistent electric field, use was made of the Poisson-Boltzmann approximation with a model electron density distribution. The paper analyzes the pattern of free-molecular nonisothermal plasma flow past a conducting cylinder - conducting strip system and introduces numerical parameters that determine the features of flow past the body system under consideration and the current collection by the cylinder. The ion current to a charged cylinder in a cross flow was calculated as a function of the cylinder potential, the degree of plasma nonisothermality, and the position of the cylinder relative to a conducting surface whose potential is close to the floating one. The numerical simulation made it possible to find quantitative characteristics of the effect of a conducting surface on the collection of the ion current by a charged cylinder. The results may be used in the development of scientific and process diagnostic instruments that interact with a low-temperature rarefied plasma flow and in the design of structural elements for advanced spacecraft and space systems.

Keymords rarefied nonisothermal plasma flow, cross flow past a cylinderstrip system, Vlasov-Poisson system, splitting method, nested grids, calculation of the current to a cylinder near a conducting surface.

1. Chung P., Talbot L., Touryan K. Electric Probes in Stationary and Flowing Plasmas (in Russian). Moscow: Mir, 1978. $201 \mathrm{pp}$.

2. Alpert Ya. L., Gurevich A. V., Pitaevsky L. P. Satellites in a Rarefied Plasma (in Russian). Moscow: Nauka, 1964. $382 \mathrm{pp}$.

3. Godard R., Laframboise J. Total current to cylindrical collectors in collisionless plasma flow. Planetary Space Science. 1983. V. 31. No. 3. p. 275-283.

4. $X u G$. Z. The interaction of a moving spacecraft with the ionosphere: Current collection and wake structure : Ph.D. dissertation. York University, 1992. $258 \mathrm{pp}$.

5. Choiniere E. Theory and experimental evaluation of a consistent steady-state kinetic model for twodimensional conductive structures in ionospheric plasmas with application to bare electrodynamic tethers in space : Ph.D. dissertation. University of Michigan, 2004. 288 pp.

6. Kotelnikov V. A., Uldanov S. V., Kotelnikov M. V. Transfer Processes in Near-Wall Plasma Layers (in Russian). Moscow: Nauka, 2004. 422 pp.

7. Garanin S. B. Interaction of Charged Bodies in Plasma (in Russian). Ph.D. dissertation. Moscow, 2010. 165 pp.

8. Lazuchenkov D. N. Calculation of an electron-repulsing self-consistent electric field near a cylinder in a rarefied plasma flow (in Russian). Teh. Meh. 2012. No. 4. Pp. 27-35.

9. Lazuchenkov D. N., Lazuchenkov N. M. Simulation of interactions between rarified plasma flow and faired charged conducting cylinder near conducting surface (in Russian). Teh. Meh. 2014. No. 2. Pp. 63-72.

10. Lazuchenkov D. N., Lazuchenkov N. M. Mathematical simulation of a supersonic collisionless plasma flow around a conducting cylinder (in Russian). Teh. Meh. 2019. No. 1. Pp. 63-74.

11. Gurevich A. V., Pitaevskii L. P., Smirnova V. V. Ionospheric aerodynamics (in Russian). Uspekhi Fizicheskikh Nauk. 1969. V. 99. No. 1. Pp. 3-49.

12. Latramboise J. G. Theory of Spherical and Cylindrical Langmuir Probes in a Collisionless Maxwellian Plasma at Rest. Report, No. 100. Univ. of Toronto, Institute of Aerospace Studies. 1966. 210 pp.

13. Alekseev B. V., Kotelnikov V. A. Probe Method for Plasma Diagnostics. Moscow: Energoatomizdat, 1988. 240 pp.

14. Granovsky V. L. Electric Current in a Gas. In 2 volumes. V. 1. General Issues of Gas Electrodynamics (in Russian). Moscow: Gostekhizdat, 1952. 432 pp. 